\title{
PENINGKATAN PENGETAHUAN PENCEGAHAN HIPERTENSI PADA MASA PANDEMI COVID-19
}

\author{
Yoanita Widjaja ${ }^{1}$, Winny Tjongarta ${ }^{2}$, Windy Hazmi Fadhilah ${ }^{3}$ \\ ${ }^{1}$ Bagian Patologi Klinik, Fakultas Kedokteran, Universitas Tarumanagara Jakarta \\ Email: yoanitaw@fk.untar.ac.id \\ ${ }^{2}$ Mahasiswa Fakultas Kedokteran Universitas Tarumanagara Jakarta \\ Email: Winny.405190004@stu.untar.ac.id \\ ${ }^{3}$ Mahasiswa Fakultas Kedokteran Universitas Tarumanagara Jakarta \\ Email: windyhazmi@gmail.com
}

\begin{abstract}
Uncontrolled blood pressure can cause fatal complications for the patients. The high number of hypertension patients in Indonesia, especially in Jakarta is caused by a lack of self-awareness and low motivation from families. Those encourage the team to conduct education activities related to preventing high blood pressure and tips so that blood pressure can be controlled. The team coordinated with West Jakarta Tomang sub-district citizens in the implementation of community service so that health education activities can be realized. This activity is carried out by providing health education related to the ways in preventing hypertension and the benefits of it during this pandemic situation. The target people of the activity is young adults in West Jakarta area, especially those with risk factors related to hypertension, hypertension patients and their families. The activity was attended by 38 participants in accordance with the target of counseling activities. The result of the average pre-test score was 35.09 and the post-test average score was 62.28; there was an increase in the knowledge of participants who attended this education about 77.5\%. This activity and other similar activities need to be carried out routinely so that the people can apply healthy life habits consistently.
\end{abstract}

Keywords: hypertension, hypertension prevention, health education

\begin{abstract}
ABSTRAK
Tekanan darah yang tidak terkontrol dapat menimbulkan komplikasi dan berakibat fatal bagi penderitanya. Masih tingginya angka kejadian hipertensi di Indonesia terutama di Jakarta, disebabkan karena kurangnya kesadaran diri serta rendahnya motivasi dari keluarga. Hal tersebut mendorong tim pengabdian melakukan edukasi terkait pencegahan tekanan darah tinggi serta kiat-kiat agar tekanan darah dapat terkontrol. Tim pengabdian berkoordinasi dengan kader kelurahan Tomang Jakarta Barat dalam pelaksanaan pengabdian masyarakat agar kegiatan edukasi kesehatan dapat terealisasi. Pelaksanaan pengabdian kepada masyarakat dilakukan dengan memberikan edukasi kesehatan terkait informasi cara pencegahan hipertensi serta manfaat pencegahan hipertensi pada masa pandemi. Sasaran dari kegiatan adalah dewasa muda di daerah Jakarta Barat terutama yang memiliki faktor resiko terkait hipertensi, penderita hipertensi dan keluarganya. Kegiatan dihadiri 38 peserta yang sesuai dengan target sasaran kegiatan penyuluhan. Hasil nilai rata-rata pre-tets adalah 35,09 dan nilai rata-rata post-test adalah 62,28, terjadi peningkatan pengetahuan peserta yang mengikuti edukasi dengan materi pencegahan hipertensi sebesar 77,5\%. Kegiatan pengabdian ini dan kegiatan serupa perlu dilaksanakan secara rutin agar perubahan gaya hidup dapat diterapkan secara konsisten oleh masyarakat.
\end{abstract}

Kata kunci: hipertensi, pencegahan hipertensi, edukasi kesehatan

\section{PENDAHULUAN}

Hipertensi telah menjadi masalah kesehatan global termasuk di Indonesia. Berdasarkan Riset Kesehatan Dasar (Riskesdas) tahun 2018, angka kejadian hipertensi tahun 2013 adalah 27,8\% dan tahun 2018 angka ini meningkat menjadi sebesar 34,1\% (Riskesdas, 2018). Tekanan darah yang tidak terkontrol dapat menyebabkan komplikasi pada organ tubuh seperti ginjal, jantung, otak, retina mata, dan pembuluh darah (Lukito A, 2019).

Pada tahun 2025 diperkirakan prevalensi penderita hipertensi di dunia akan ada sebanyak 1,56 milyar dan paling banyak ditemui pada dewasa muda (Bell, K., et al., 2015). Hipertensi disebut the silent killer karena seringkali tidak menimbulkan gejala, tetapi bertanggung jawab terhadap 
13,5\% dari seluruh kematian akibat penyakit kardiovaskular (Ghadieh, A. S., et al., 2015). Empat puluh lima persen kematian karena hipertensi disebabkan oleh penyakit kardiovaskular, sedangkan 55\% disebabkan stroke (Kjeldsen, S., et al., 2014).

Pada keadaan pandemi Covid-19 saat ini, tekanan darah merupakan hal yang perlu dikontrol agar tidak menambah beban penyakit. Terdapat beberapa penyakit yang membutuhkan perhatian lebih karena penderita penyakit ini lebih rentan terkena penyakit Covid-19 dan jika terkena, dapat menimbulkan gejala klinis Covid-19 yang lebih berat. Kelompok penyakit ini disebut penyakit komorbid. Hipertensi merupakan penyakit komorbid Covid-19 yang terbanyak. Berdasarkan data dari satuan tugas penanganan Covid-19 pada Oktober 2020, jumlah pasien Covid-19 yang memiliki penyakit komorbid yaitu sebanyak 1.488 pasien dan 50,5\% nya menderita hipertensi (Rokom, 2021).

Tekanan darah harus selalu terkontrol pada angka $120 \mathrm{mmHg}$ sistolik dan $80 \mathrm{mmHg}$ diastolik pada orang dewasa normal. Hal ini penting tidak hanya untuk menghindari gejala berat dari Covid-19, tetapi juga untuk mencegah komplikasi dari penyakit hipertensi itu sendiri. Tekanan darah yang meningkat mendadak dapat menyebabkan kerusakan organ. Banyak orang tidak peduli untuk mengontrol tekanan darahnya, padahal keadaan ini dapat memicu timbulnya komplikasi serta mempercepat kerusakan pada jantung dan pembuluh darah, serta memicu timbulnya penyakit lain seperti stroke (WHO, 2013). Tekanan darah tinggi yang tidak terkontrol dan sudah diikuti komplikasi, menempati urutan ke lima sebagai penyebab kematian pada semua golongan usia. Pada tahun 2017, penyakit tidak menular sebagai penyebab kematian pertama di Indonesia yaitu stroke yang disebabkan tekanan darah tinggi yang tidak terkontrol (Institute for Health Metrics and Evaluation, 2018; Usman, et al., 2019).

Hipertensi merupakan penyakit kronik yang dapat menimbulkan berbagai komplikasi. Jika seseorang memiliki faktor risiko seperti kelebihan berat badan, keturunan hipertensi, usia yang semakin meningkat, serta pola makan dan gaya hidup yang tidak sehat, maka ia harus lebih memerhatikan langkah-langkah pencegahan hipertensi, karena ia lebih rentan terkena penyakit tersebut (Bell, K., et al., 2015). Pencegahan selalu lebih baik daripada mengobati. Pencegahan sederhana yang dapat dilakukan yaitu mengukur tekanan darah secara teratur serta menjaga pola hidup yang baik. Kesadaran seseorang, peran keluarga, serta pengetahuan yang dimiliki berkontribusi dalam kepatuhan menjalankan modifikasi pola hidup untuk mencegah hipertensi. Selanjutnya, hal ini dapat menurunkan prevalensi dan insiden peningkatan tekanan darah secara mendadak (Novian, A., 2013).

Hipertensi menjadi berbahaya karena jarang menunjukkan gejala, sehingga sebagian besar penderita hipertensi tidak menyadari jika ia mengalami tekanan darah yang tidak terkontrol (Kementerian Kesehatan Republik Indonesia, 2017). Oleh karena itu, pengukuran tekanan darah rutin merupakan salah satu upaya pencegahan dan deteksi dini hipertensi. Deteksi dini sebaiknya dimulai sejak dewasa muda dan tidak menunggu hingga usia tua, walaupun usia disebut merupakan salah satu faktor yang dapat meningkatkan kejadian hipertensi. Pada kenyataannya, hipertensi terdeteksi pada kelompok usia muda hingga tua, yaitu usia 31-64 tahun. Deteksi dini perlu diikuti dengan pengetahuan mengenai cara pencegahan hipertensi, karena diketahui bahwa kurangnya self management serta kurangnya pengetahuan dapat meningkatkan kejadian hipertensi (Wulansari, J., et al., 2013). Hal tersebut mendorong tim pengabdian kepada masyarakat Fakultas Kedokteran Universitas Tarumanagara (FK Untar) melakukan edukasi pencegahan hipertensi pada warga. Edukasi diberikan pada warga Tomang, Jakarta mengingat hipertensi merupakan penyakit terbanyak yang ditemukan pada layanan rawat jalan di Puskesmas DKI Jakarta tahun 2020 (Portal Data Terpadu Pemprov DKI Jakarta, 2021).

\section{METODE PELAKSANAAN PKM}


Pelaksanaan kegiatan pengabdian ini diawali dengan rapat internal anggota tim pengabdian yang membahas tanggal pelaksanaan, target kegiatan serta materi penyuluhan. Selanjutnya, tim pengabdian berkoordinasi dengan perwakilan peserta edukasi untuk mengoordinir pendaftaran dengan mengisi google form dalam flyer yang dibagikan tim pengabdian 1 minggu sebelum pelaksanaan kegiatan. Sasaran kegiatan adalah dewasa muda di daerah Jakarta Barat khususnya warga Kelurahan Tomang yang terutama memiliki faktor resiko terkait hipertensi, serta penderita hipertensi dan keluarganya.

Kegiatan edukasi dilakukan tanggal 2 Oktober 2021 pk. 09.00-10.00. Pada saat diselenggarakannya kegiatan ini, pemerintah Jakarta sedang memberlakukan pembatasan pergerakan dan kegiatan masyarakat, sehingga kegiatan dilakukan secara daring menggunakan aplikasi zoom. Media yang digunakan yaitu power point presentation dan video. Materi yang disampaikan pada kegiatan edukasi meliputi pencegahan hipertensi melalui pengaturan pola makan dan gaya hidup. Selain itu peserta juga diperkenalkan tentang pencegahan hipertensi dengan enam langkah yang disingkat CERDIK (Cek kesehatan secara rutin, Enyahkan asap rokok, Rajin aktivitas fisik, Diet seimbang, Istirahat cukup, Kelola stres). Kegiatan diawali dengan pre-test untuk menilai pengetahuan awal terkait pencegahan hipertensi dan setelah pemaparan materi dilakukan post-test untuk menilai manfaat kegiatan edukasi ini bagi peserta. Pre-test dan post-test dilakukan menggunakan google form.

\section{HASIL DAN PEMBAHASAN}

Kegiatan pengabdian kepada masyarakat dengan topik "Cegah Hipertensi" dilaksanakan pada hari Sabtu tanggal 2 Oktober 2021 pk. 09.00-10.00. Kegiatan pengabdian dihadiri 38 peserta yang telah mendaftar pada link pendaftaran yang terdapat di flyer kegiatan seperti yang dapat dilihat pada gambar 1 .

Pelaksanaan edukasi diawali dengan pre-test. Setelah semua peserta mengisi pre-test, tim pengabdian mulai menyampaikan materi terkait pencegahan hipertensi. Peserta diputarkan video terkait pencegahan hipertensi yang efektif, alasan pencegahan hipertensi perlu dilakukan, serta hal-hal yang dapat terjadi jika tidak melakukan pencegahan sejak dini. Tim pengabdian juga memamparkan tentang CERDIK yaitu cek tekanan darah secara rutin, enyahkan asap rokok, rajin beraktivitas fisik, diet seimbang, istirahat cukup dan kelola stres. Singkatan CERDIK diinformasikan pada peserta agar mereka dapat mengingat cara-cara pencegahan dengan lebih mudah. Tim pengabdian mengingatkan agar peserta menerapkan CERDIK dalam pencegahan hipertensi di kehidupan sehari-hari. 


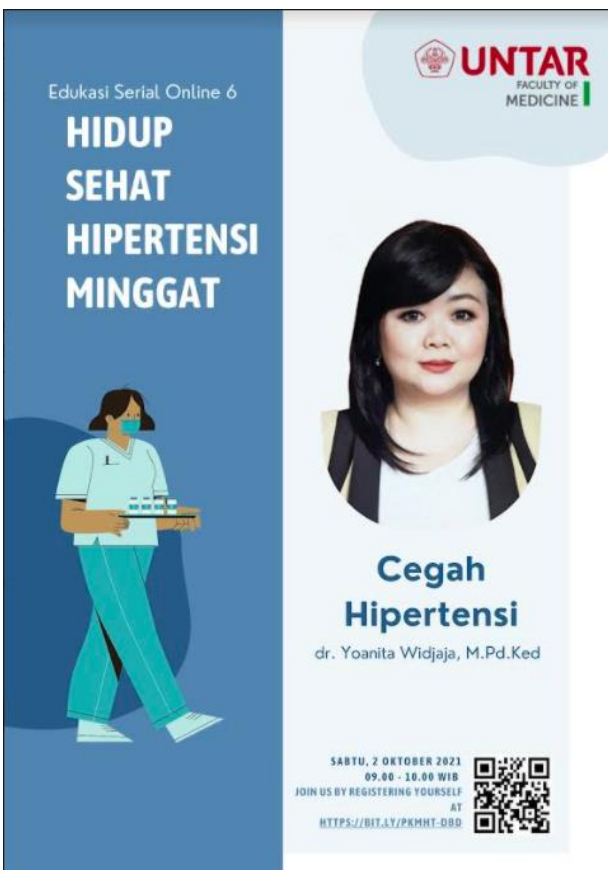

Gambar 1. Flyer kegiatan

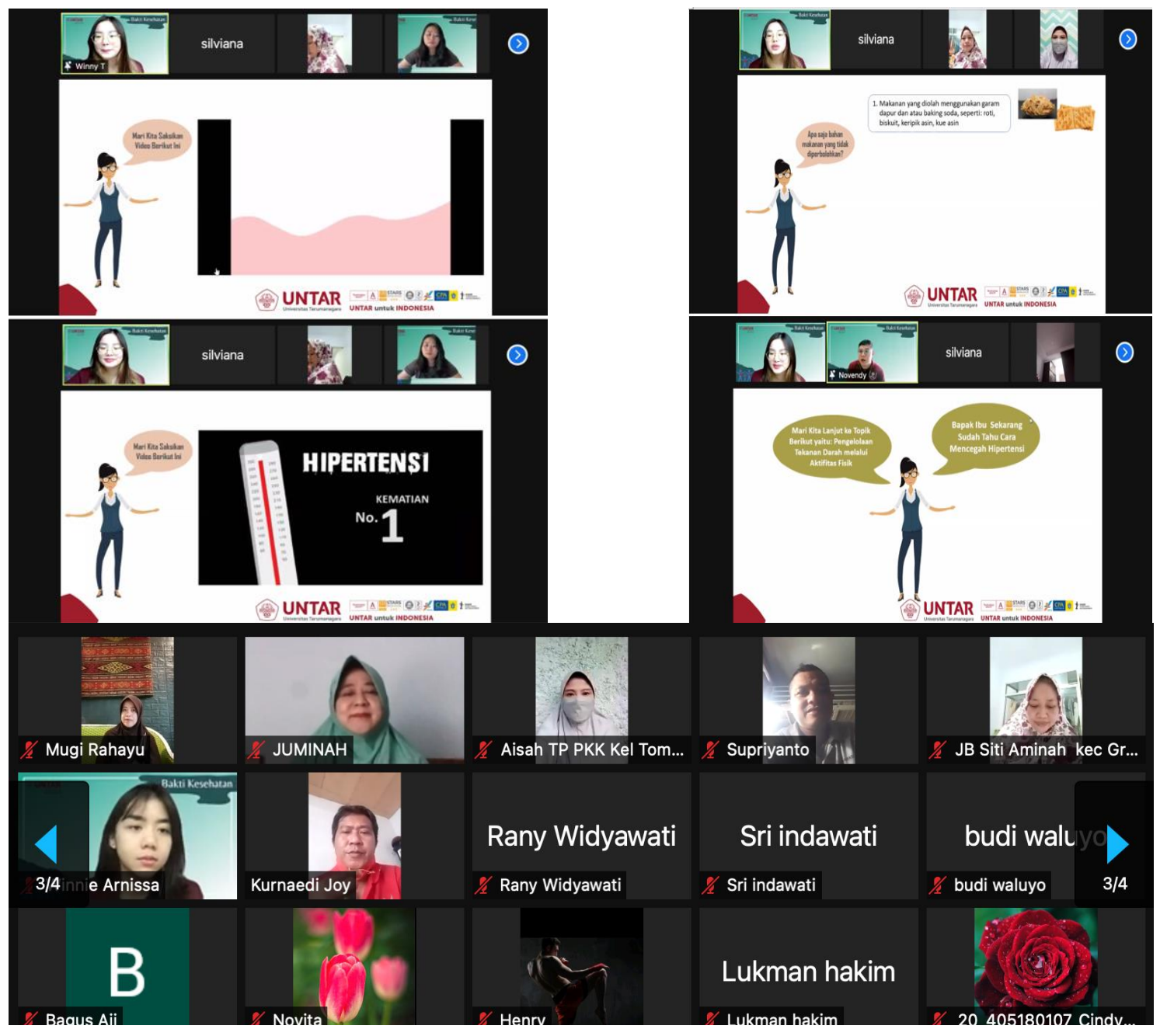

Gambar 2. Acara edukasi 


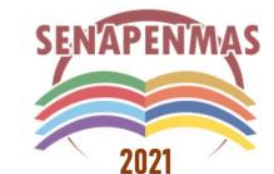

2021
Seminar Nasional Hasil Penelitian dan Pengabdian Kepada Masyarakat 2021

Pengembangan Ekonomi Bangsa Melalui Inovasi Digital Hasil Penelitian dan Pengabdian Kepada Masyarakat Jakarta, 21 Oktober 2021
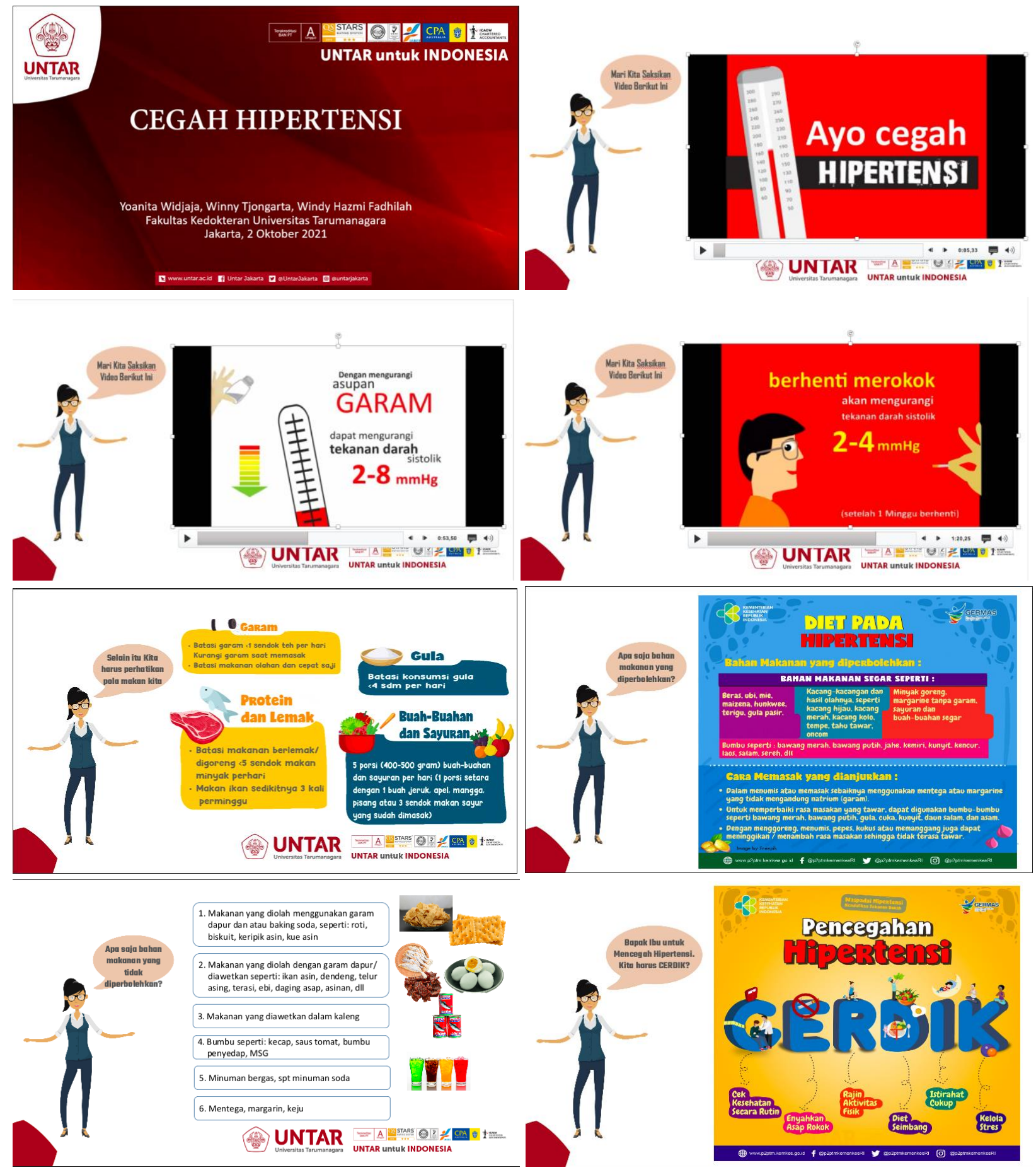

Gambar 3. Materi penyuluhan

Peserta pengabdian mengikuti kegiatan dengan semangat, semua peserta mengisi pre-test dan post-test dengan lengkap. Pre-test disampaikan sebelum pemaparan materi penyuluhan bertujuan menilai pengetahuan awal peserta terkait pencegahan hipertensi dan nilai rata-rata yang dicapai dari seluruh peserta adalah 35,09. Setelah penyampaian materi untuk menilai manfaat dari edukasi pencegahan hipertensi dilakukan post-test dan didapatkan nilai rata-rata adalah 62,28. Berdasarkan hasil pre-test dan post-test terjadi peningkatan nilai rata-rata sebesar $77,5 \%$ setelah penyampaian materi. 
Peningkatan tersebut menunjukkan bahwa edukasi kesehatan terkait pencegahan hipertensi telah mencapai target jangka pendek, yaitu peningkatan pengetahuan untuk pencegahan hipertensi yang selanjutnya diharapkan dapat menumbuhkan kesadaran pentingnya pola hidup sehat guna mencegah hipertensi. Berdasarkan umpan balik yang diperoleh dari peserta, mereka menyatakan senang mendapatkan informasi kesehatan seperti hipertensi ini karena hipertensi merupakan penyakit yang seringkali mereka temui dalam lingkup keluarga mereka. Edukasi ini juga menambah wawasan para peserta terkait cara-cara pencegahan hipertensi yang sederhana dan dapat dilakukan sehari-hari. Peserta mengusulkan agar kegiatan ini dapat berlangsung secara berkelanjutan dan periodik. Peserta juga menyampaikan bahwa kegiatan edukasi pencegahan hipertensi pada masa pandemi Covid-19 ini penting karena hipertensi merupakan salah satu penyakit komorbid yang sering ditemui.

\section{KESIMPULAN DAN SARAN}

Kegiatan pengabdian kepada masyarakat yang merupakan bentuk dari pelaksanan tridharma pendidikan diselenggarakan Sabtu 2 Oktober 2021 pk. 09.00-10.00 dengan mengambil topik "Cegah Hipertensi" berjalan dengan baik. Kegiatan dihadiri 38 peserta yang sesuai dengan target sasaran kegiatan penyuluhan. Hasil nilai rata-rata pre-test adalah 35,09 dan nilai ratarata post-test adalah 62,28 menunjukkan terjadinya peningkatan pengetahuan peserta yang mengikuti edukasi dengan materi pencegahan hipertensi sebesar 77,5\%. Kegiatan edukasi mengenai hipertensi atau penyakit lainnya perlu dilaksanakan agar dapat mengarahkan pandangan masyarakat untuk hidup sehat serta meningkatkan kesadaran untuk mencegah penyakit karena mencegah lebih baik daripada mengobati. Kegiatan dapat dilakukan secara rutin agar warga Tomang dapat konsisten menerapkan gaya hidup sehat.

\section{Ucapan Terima Kasih (Acknowledgement)}

Penulis mengucapkan terima kasih kepada Lembaga Penelitian dan Pengabdian kepada Masyarakat (LPPM) UNTAR untuk bantuan pendanaan kegiatan ini. Terima kasih juga kepada Rektor Untar dan Dekan FK Untar beserta jajarannya yang mendukung kegiatan PKM ini. Penulis mengucapkan terima kasih juga kepada para peserta yang telah ikut serta dalam kegiatan edukasi ini sehingga dapat berjalan dengan lancar.

\section{REFERENSI}

Novian, A. (2013). Kepatuhan diit pasien hipertensi. Jurnal Kesehatan Masyarakat, 9 (1). http://journal.unnes.ac.id/nju/index.php/kemas.

Ghadieh, A. S., Saab, B. (2015). Evidence for exercise training in the management of hypertension in adults. Can Fam Phys. 2015; 61(3): 233-9. https://pubmed.ncbi.nlm.nih.gov/25927108/

Institute for Health Metrics and Evaluation (IHME). (2018). Findings from the global burden of disease study 2017. IHME. http://www.healthdata.org/policy-report/findingsglobal-burden-disease-study-2017

Bell, K., Twiggs, J., Olin, B. R. (2015). Hypertension: The silent killer: Update JNC 8 guideline recommendation. Alabama Pharmacy Association. https://cdn.ymaws.com/www.aparx.org/resource/resmgr/CEs/CE_Hypertension_The_ $\underline{\text { Silent_K.pdf }}$ 
Kementerian Kesehatan Republik Indonesia. (2017). Hipertensi. Infodatin Pusat Data dan Informasi Kementerian Kesehatan Republik Indonesia. https://pusdatin.kemkes.go.id/resources/download/pusdatin/infodatin/infodatinhipertensi.pdf

Kjeldsen, S., Feldman, R. D., Lisheng, L., Mourad, J. J., Chiang, C. E., Zhang, W., et al. (2014). Updated national and international hypertension guidelines: A review of current recommendations. drugs. 2014;74(17):2033-51. https://pubmed.ncbi.nlm.nih.gov/25315030/

Lukito, A. A, Harmeiwaty, E., Hustrini, N. M. (Eds.). (2019). Konsensus penatalaksanaan hipertensi 2019. Perhimpunan Dokter Hipertensi Indonesia.

Portal Data Terpadu Pemprov DKI Jakarta. (2021). Data 10 penyakit terbanyak rawat jalan di puskesmas DKI Jakarta tahun 2020. https://data.jakarta.go.id/dataset/10-penyakitterbanyak-rawat-jalan-di-puskesmas-dki-jakarta-tahun-2020

Riskesdas. (2018). Laporan riset kesehatan dasar (riskesdas). Jakarta: Departemen Kesehatan Republik Indonesia https://www.litbang.kemkes.go.id/laporan-riset-kesehatan-dasarriskesdas/

Rokom. (2021). 13,2 persen pasien Covid-19 meninggal memiliki penyakit hipertensi. https://sehatnegeriku.kemkes.go.id/baca/umum/20201013/5535336/132-persen-pasiencovid-19-meninggal-memiliki-penyakit-hipertensi/

Usman, Y., Iriawan, R. W., Rosita, T., Lusiana, M., Kosen, S., Kelly, M., ... Raoi, C. (2019). Indonesia's sample registration system in 2018: A work in progress. Journal of Population and Social Studies, 27(1), 39-52.

WHO. (2013). A global brief on hypertension. https://www.who.int/cardiovascular_diseases/publications/global_brief_hypertension/en/

Wulansari, J., Ichsan, B., Usdiana, D. (2013). Hubungan pengetahuan tentang hipertesi dengan pengendalian tekanan darah pada pasien hipertensi di poliklinik penyakit dalam RSUD DR. MOEWARDI SURAKARTA, Biomedika, 5(1), 17-22. https://journals.ums.ac.id/index.php/biomedika/article/view/271 
Seminar Nasional Hasil Penelitian dan Pengabdian Kepada Masyarakat 2021

Pengembangan Ekonomi Bangsa Melalui Inovasi Digital Hasil Penelitian dan

Pengabdian Kepada Masyarakat

Jakarta, 21 Oktober 2021

(halaman kosong) 